\title{
Investigating the Cause of Poor Efficiency in Thermal Power Plant - A Six-Sigma based Case Study
}

\author{
Manjeet Kharub ${ }^{1}$, Garuav Sharma ${ }^{2}$, Sarat Kumar Sahoo ${ }^{3}$ \\ ${ }^{1}$ Asst. Professor, CVR College of Engineering/Mechanical Department, Hyderabad, India \\ Email: manjeetkharub@gmail.com \\ ${ }^{2}$ Asst. Professor, CVR College of Engineering/ECE Department, Hyderabad, India \\ Email: ergaurav209@yahoo.co.in \\ ${ }^{3}$ Asst. Professor, CVR College of Engineering/Mechanical Department, Hyderabad, India \\ Email: saratkumar222@gmail.com
}

\begin{abstract}
Nowadays, energy in any form has become an essential commodity all over the world. Being a developing country India is facing energy shortage problems. The Indian government is investing into various projects for efficient utilisation of available resources and to improve power plant efficiency. Research scholars and agencies are seeing the quality of thermal power plant is a possible area of improvement. This paper focuses on identifying the causes of capacity waste in a thermal power plant. For this Six-Sigma improvement project, DMAIC (Define-measure-analysisimprove-control) approach has been adopted. The study found low availability of equipment is the primary cause of capacity wastage in a thermal power plant. Various suggestions were provided to reduce equipment availability problem and consequently to improve the plant efficiency.
\end{abstract}

Index Terms: Quality, Six-Sigma Approach, Thermal power plants, Low equipment Availability.

\section{INTRODUCTION}

The growth in the Indian economy is accompanied by higher demand in the energy sector, i.e., renewable and nonrenewable (3.6\% increase per annum) [1]. To cope with the current situation Indian government is perusing ambitious energy expansion programs [2]. Since 2016, the level of wind power generation capacity has been doubled, and solar power has increased almost 15 fold. Thermal power plants are the primary source of electricity generation in India [3]. At present, the power generation through different sources is uneven as approximately:

- Thermal plants $(63 \%)$;

- Hydropower contribution (25\%);

- Nuclear power (3\%);

- Renewable source (9\%).

Still, India is not able to meet the growing energy demand from industries, and a gap between supply and demand is continuously increasing [4]. Around $1 / 4$ of the total population is still deprived of access to electricity. Currently, the estimated average gap between supply and demand of electricity (peak demand) is about 14\% [5]. The power scenario is seeming constant to be wicked indeed the country has geared up to expand power supply to link the large gap. The government has already taken measure to improve the current positions by undertaking power projects
[6]. The action plan has been drawn up, which involves short-term, medium-term and long-term measures.

Short term: these projects involve overhaul and maintenance of existing equipment (boilers) and offer optimal operational performance. The short-term plans are employed for the constant increase in Plant Load Factor (PLF).

Medium term: is employed to have a significant improvement in the PLF of a power station. The mediumterm project offers proper maintenance planning to the full plant.

Long-term: renovation and moderation programmes can improve the availability factors in old plants.

The common purpose of these programmes (short, medium and large) is to improve the installed capacity of thermal power plants by:

- Adopting supercritical technology

- Providing maintenance policy;

- Reducing the distribution losses;

- Improving the plant availability;

- Modernization and renovation of Power Plant.

The above-stated steps are considered as vital to increasing plant capacity, to minimise cost and maximise profits. The steps are effectively applicable only when they are allying with a systematic approach. Based on discussion Six Sigma can be considered a conventional method [7]. Six Sigma has been adopted by many organisations worldwide with an aim to improve process performance and come out with many success stories [8]. The five steps for improvements under Six Sigma programs are Define-Measure- AnalyzeImprove- Control (DMAIC). As shown in Table I and Table II.

TABLE I.

SIGMA AND CORRESPONDING DEFECTED PPM

\begin{tabular}{|c|c|c|}
\hline Sigma Level & Percent Yield & PPM \\
\hline $6 \sigma$ & $99.9997 \%$ & 3.4 \\
\hline $5 \sigma$ & $99.98 \%$ & 233 \\
\hline $4 \sigma$ & $99.4 \%$ & 6,210 \\
\hline $3 \sigma$ & $93.3 \%$ & 66,807 \\
\hline $2 \sigma$ & $69.1 \%$ & 308,537 \\
\hline $1 \sigma$ & $30.9 \%$ & 691,462 \\
\hline
\end{tabular}


TABLE II.

EXPLAINING DMAIC APPROACH

\begin{tabular}{|c|c|c|c|c|}
\hline Define & Measure & Analysis & Improve & Control \\
\hline 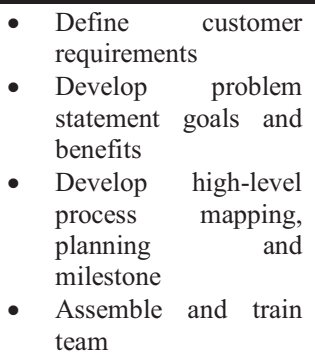 & $\begin{array}{l}\text { - Define "defect" and } \\
\text { opportunity units and } \\
\text { metrics } \\
\text { - Develop detailed process } \\
\text { maps of appropriate areas } \\
\text { - Collect data for relevant } \\
\text { metrics } \\
\text { - Develop process capability } \\
\text { baseline } \\
\text { - Establish current process } \\
\text { sigma level }\end{array}$ & $\begin{array}{l}\text { - Develop "causal" } \\
\text { hypothesis } \\
\text { - Identify vital few } \\
\text { cause } \\
\text { - Validate hypothesis } \\
\text { - Quantifying the gap } \\
\text { and improvement } \\
\text { opportunity }\end{array}$ & $\begin{array}{l}\text { - Develop ideas to remove } \\
\text { the root cause } \\
\text { - Validate potential } \\
\text { improvement ideas } \\
\text { through pilot studies } \\
\text { - Standardize solution } \\
\text { - Measure results } \\
\text { - Develop improvement } \\
\text { plan }\end{array}$ & $\begin{array}{l}\text { - Establish standard } \\
\text { measure to monitor } \\
\text { performance } \\
\text { - Determine process } \\
\text { capability continuously } \\
\text { - Correct problems and } \\
\text { needed } \\
\text { - Document best process }\end{array}$ \\
\hline
\end{tabular}

Six Sigma is a well-structured program used by various industries to achieve expected performance with continuous improvement [9]. Six Sigma stands for six standard deviation (Sigma is a Greek letter used to represent variation in statistics) from the mean. Six Sigma methodologies provide the tool and technique to improve the performance and minimise the defects in any process. The higher the sigma level, the better will be the process. Table I shows that defective part per million (PPM) opportunities decreases as Sigma level goes high.

\section{Capacity Waste In Thermal Power Plants}

In power generation industry boiler is most crucial equipment particularly for thermal power plants, cements plants, coal plants and paper mills [10]. It is used to heat the water to convert it into steam. The variation in a thermal power plant is only due to the source of boiler fuel (i.e., coal, naphtha, natural gases). Globally, these conventional fuels are going to be exhausted [11]. Organizations are either focusing on non-conventional sources of energy or trying to improve the efficiency of existing systems.

The efficiency of any heating system is defined as the ratio of positive work done to the heat input [12]. As per the study by NTPC, the maximum efficiency is obtained as $35 \%$ with a cost of $65 \%$ heat losses due to the results of burning of coal in boilers. Plant capacity is defined in three ways:

i. Design Capacity: Maximum possible obtainable output. In this case, it is the maximum quantity of steam a boiler can produce minimum fuel consumption.

ii. Effective Capacity (Expected Variations): The maximum capacity obtained with the help of proper plant maintenance.

iii. Actual Capacity/output: Rate of production achieved can't exceed productive capacity. As calculated by the formulas given in Table III.

TABLE III.

THermal Power Plant Efficiency CAlculation

\begin{tabular}{lll}
\hline Efficiency $=$ & {$[($ Actual capacity/Output)/(Effective } \\
& Capacity) $]$ X100\%. \\
& {$[\{$ Actual capacity(AC)/Output $\} /\{$ Design } \\
Capacity utilization & capacity (DC) $\}]$ X100\%. \\
So, we can find the capacity waste as & $=1-$ Capacity utilization (C.U) \\
Capacity waste (C.W.) $=$ & $1-[$ Actual capacity/Design capacity $]$ \\
\hline
\end{tabular}

It is subject to unplanned disruptions; machine failure, desertion, material deficiency and most importantly the demand. These different types of capacity are beneficial to find the efficiency and plant utilization. The optimum utilisation of above-discussed capacities is essential.

\section{Six Sigma Role In Reducing Capacity WaSte}

Six Sigma is a conventional technique in quality management primarily aimed to eliminate detects, minimise mistakes and failure in any process [7]. The successful implementation of Six-Sigma techniques has been well documented in renowned organisations. From last two decades, organisations are appreciating the positive results obtained from Six-Sigma implementation [13]. In literature, the success of Six Sigma in the automobile industry, food industry, rubber industry, plastic industry, at large and small level, is well documented [14]. However, there is still less documented evidence available for its successful implementation in thermal power plants. Mainly the concept of Six Sigma has been applied in many manufacturing and service industry; still, there is an excellent research gap is available to see the benefits of Six Sigma in process industries. To fill this gap author conducted a case study.

\section{CASE Study Design}

A case study has been carried in a thermal power plant processing in a northern part of the country. The capacity of plant detail is given below:

\begin{tabular}{ll}
\hline CAPACITY & 600MW $(2 * 300)$ \\
PROJECT COST & 2400 CRORE \\
LAND & 1107 (ACRE) \\
DATE OF START CONS & 20.08 .2005 \\
GENERATING CAPACITY & 144 LACS UNIT\DAY \\
\hline
\end{tabular}

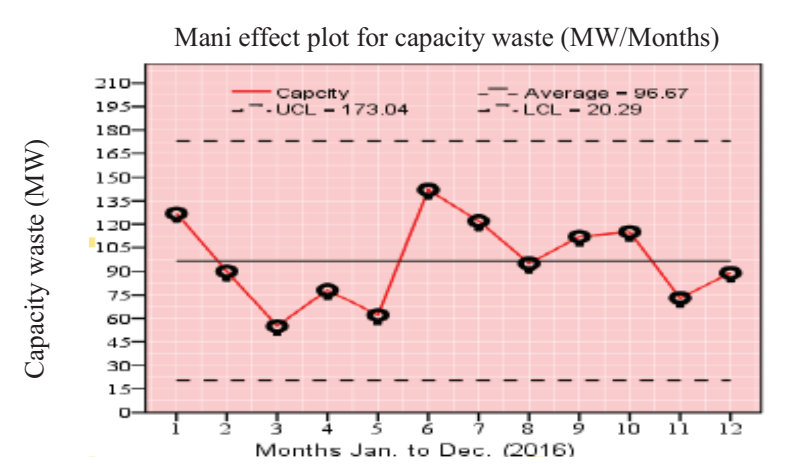

Figure 1. Capacity waste analysis 
The plant was operating in two units. In this case study for the application of Six Sigma in process industry unit-II was selected.

Step - I: the Six Sigma steps (define-measure-analysisimprove-control) were applied to define problem relevant to capacity wastage. From previous records, last six months data (i.e., from July - December 2016) was taken and capacity wasted per month was calculated with the help of primary effect analysis. Fig. 1 shows capacity waste analysis. With the help of individual moving charts, sigma levels of capacity wastage were calculated as presented in Table IV.

TABLE IV

CaPacity Wastage At Different Sigma LeVEls

\begin{tabular}{|l|l|l|l|l|}
\hline $\begin{array}{l}\text { Sigma } \\
\text { level }\end{array}$ & UCL & LCL & $\begin{array}{l}\text { Process } \\
\text { Width }\end{array}$ & Average \\
\hline $1 \sigma$ & 122.13 & 71.21 & 50.92 & 96.67 \\
\hline $2 \sigma$ & 147.45 & 45.75 & 101.83 & 96.67 \\
\hline $3 \sigma$ & 173.04 & 20.29 & 152.75 & 96.67 \\
\hline $4 \sigma$ & 198.50 & -5.17 & 203.67 & 96.67 \\
\hline $5 \sigma$ & 223.96 & -30.63 & 254.59 & 96.67 \\
\hline $6 \sigma$ & 249.42 & -56.09 & 305.51 & 96.67 \\
\hline $\begin{array}{l}\text { UCL: Upper Control Limit } \\
\text { LCL: Lower Control Limit }\end{array}$ \\
\hline
\end{tabular}

From Table IV it is clear that process width is directly proportional to sigma level. In an ideal situation, the process width should be minimum as possible. In another word, the variation in plant's capacity should occur less as possible and for this plants need improvements projects. The average capacity waste was found $96.67 \mathrm{MW} /$ month, which is having a substantial financial and non-financial loss.

Step - II: step one cleared that to improve plant efficiency process width needs to be reduced. So, in step-II, we conducted a brain-storming session with engineers, and supervisors asked the following questions:

Q1: What can be the possible reasons for increased process width or primary cause of this capacity waste?

Q2: How the capacity wastage related to different instruments?

Q3. What is the prime source behind capacity wastage in thermal power plants?

To find out the answers to these questions, based on discussion and available data main reason of capacity wastage were calculated as presented with the help of a pie chart in Fig. 2.

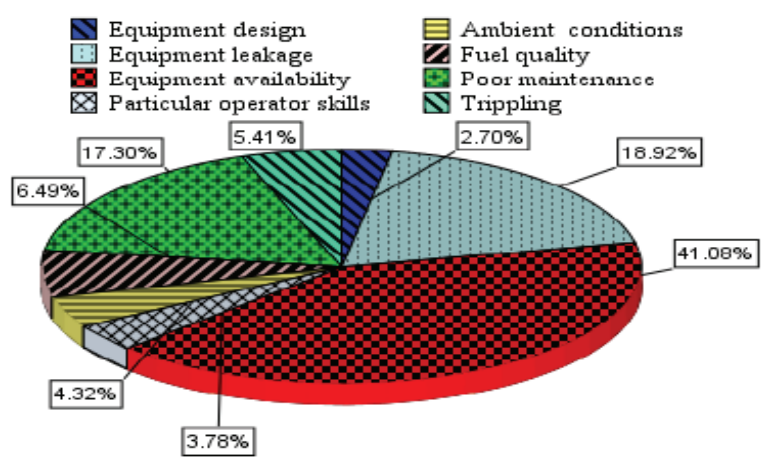

Figure 2. Percent Contribution of different factors
From pie chart, the main reasons were found as:

i. low equipment availability $(41.08 \%)$;

ii. equipment leakage (18.92\%);

iii. reduced maintenance $(17.30 \%)$;

iv. fuel quality $(63.49 \%)$;

v. tripling $(5.41 \%)$;

vi. ambient conditions $(4.32 \%)$;

vii. operator skills (3.78\%); and

viii. equipment design problem $(2.70 \%)$.

So, it was observed that the most severe cause for capacity waste was low availability.

\section{RESEARCH IMPLICATION}

- To improve overall availability following suggestion were given:

- Divide the main problem into some small sections. Such as input material (coal) handling system, power generating unit, air system, ash handling, and fuel and condensation system.

- Draw a Pareto analysis chart to deal with few significant problems first.

- Use of simulation and optimisation models to improve equipment availability.

- Calculate the \% contribution of different sections based on optimise value.

- To calculate the overall impact of the project in term of finance and plant efficiency.

- Re-design the same project with considering the unusual problem with an aim to improve its sigma level.

\section{Conclusions}

The paper presented a case study for implementing the Six-Sigma concept in a thermal power plant. Pie charts and sigma analysis were used to priorities various problems. Based upon analysis low equipment availability was found the prime cause of capacity waste. It was suggested to subdivide the system into a different small unit such as fuel section, stream generator, boiler section, evaporator, and superheater, etc. Different modelling and optimisation techniques were suggested to improve equipment availability. It was recommended to involve employees in this type of projects. The study will be useful for managers handling various thermal power plants and for students seeking a new research area in the field of quality engineering. The future investigation can be conducted into other thermal power plants or using other quality improvement techniques with an aim to improve plant efficiency and productivity.

\section{REFERENCES}

[1] Pohekar, S.D., Kumar, D. and Ramachandran, M., "Dissemination of cooking energy alternatives in India - a review," Renewable and Sustainable Energy Reviews, vol. 9, no. 4, pp. 379-393, 2005.

[2] Ramachandra, T.V. and Shruthi, B.V., "Wind energy potential mapping in Karnataka, India, using GIS," Energy conversion and management, vol. 46, no. (9-10), pp. 1561-1578, 2005. 
[3] Bhat, I.K. and Prakash, R., "LCA of renewable energy for electricity generation systems - a review," Renewable and Sustainable Energy Reviews, vol. 13, no. 5, pp. 1067-1073, 2009.

[4] Asif, M. and Muneer, T., "Energy supply, its demand and security issues for developed and emerging economies", Renewable and Sustainable Energy Reviews, vol. 11, no. 7, pp. 1388-1413, 2007.

[5] Ghorashi, A.H. and Rahimi, A., "Renewable and nonrenewable energy status in Iran: Art of know-how and technology-gaps", Renewable and Sustainable Energy Reviews, vol. 15, no. 1, pp. 729-736, 2011.

[6] Clement, A., McCullen, P., Falcao, A., Fiorentino, A., Gardner, F., Hammarlund, K., Lemonis, G., Lewis, T., Nielsen, K., Petroncini, S. and Pontes, M.T., "Wave energy in Europe: current status and perspectives," Renewable and sustainable energy reviews, vol. 6, no. 5, pp. 405-431, 2002.

[7] Chugani, N., Kumar, V., Garza-Reyes, J.A., Rocha-Lona, L. and Upadhyay, A., "Investigating the green impact of Lean, Six Sigma and Lean Six Sigma: A systematic literature review," International Journal of Lean Six Sigma, vol. 8, no. 1, pp. 7-32, 2017.

[8] Kharub, M. and Sharma, R., "An integrated structural model of QMPs, QMS and firm's performance for competitive positioning in MSMEs," Total Quality Management \& Business Excellence, pp. 1-30, 2018.

[9] Lizarelli, F. L. and Alliprandini, D.H., "Comparative analysis of Lean and Six Sigma improvement projects: performance, changes, investment, time and complexity,". Total Quality Management \& Business Excellence, pp. 1-22, 2018.

[10] Hui, C.W. and Natori, Y., "An industrial application using mixed-integer programming technique: a multi-period utility system model," Computers \& chemical engineering, vol. 20, pp. S1577-S1582, 1996.

[11] Hoel, M. and Kverndokk, S., "Depletion of fossil fuels and the impacts of global warming," Resource and energy economics, vol. 18 , no. 2 , pp. 115-136, 1996.

[12] Hepbasli, A., "A key review on exergetic analysis and assessment of renewable energy resources for a sustainable future," Renewable and sustainable energy reviews, vol. 12, no. 3, pp. 593-661, 2008.

[13] Timans, W., Antony, J., Ahaus, K. and van Solingen, R., "Implementation of Lean Six Sigma in small-and mediumsized manufacturing enterprises in the Netherlands,". Journal of the Operational Research Society, vol. 63, no. 3, pp. 339-353, 2012.

[14] Koksal, G., Batmaz, I. and Testik, M.C., "A review of data mining applications for quality improvement in manufacturing industry," Expert systems with Applications, vol. 38, no. 10, pp.13448-13467, 2011. 